\title{
CAPÍTULO 8
}

\section{INTELIGÊNCIA EMOCIONAL APLICADA À LIDERANÇA EM UM MUNDO IMPREVISÍVEL}

\author{
Juliana Akemi Assaoka \\ Junho Nogueira de Oliveira
}

\section{APRESENTAÇÃO}

Este capítulo tem como objetivo apresentar a importância da inteligência emocional aplicada à liderança após a pandemia. O propósito é trazer embasamento para uma reflexão que possa provocar o desenvolvimento do líder. A evolução da humanidade talvez nunca tenha tido uma velocidade tão grande quanto à que vivenciamos atualmente, em 2020, propiciada pela pandemia da Covid-19. Mediante esta nova realidade de mundo, tudo torna-se imprevisível, profissões começam a desaparecer e outras a surgir, e com esta imensa insegurança, uma multidão passa a sofrer por falta de estabilidade emocional e síndromes diversas como estresse, ansiedade, depressão, pânico, chegando até mesmo a um Burnout. ${ }^{12}$ É neste contexto que se torna necessário o líder estar altamente preparado para saber gerenciar não apenas pessoas e processos, mas, também suas próprias emoções e os que o cerca.

\footnotetext{
12 Síndrome de Burnout, ou síndrome do esgotamento profissional, é um distúrbio psíquico cuja principal característica é o estado de tensão emocional e estresse crônico provocado por condições físicas, emocionais e psicológicas desgastantes no ambiente de trabalho.
} 


\section{INTRODUÇ̄̃O}

A inteligência emocional é uma das competências mais solicitadas em todo contexto relacional, dentro e fora do ambiente corporativo. Para Goleman (2007), essa habilidade torna-se essencial para construir uma vida mais harmoniosa e isso ocorre por diversas razões, a passagem por mudanças constantes, pessoas expostas a situações de extrema violência em busca de poder, consumo desenfreado, catástrofes, epidemias, ameaças ecológicas, guerras, discriminação e desigualdade, o que por sua vez proporciona grande instabilidade emocional.

A constante mudança transforma o homem, a sociedade, culturas e o modo como as coisas são feitas e a chegada da pandemia e o desenvolvimento de novas tecnologias, que acompanham a Quarta Revolução Industrial, está transformando a realidade, de maneira exponencial. O que de fato chama atenção, não são apenas as transformações ocorridas, mas sim, a velocidade em que ocorrem. Se comparar os períodos das revoluções industriais anteriores, as transições demoraram muitos anos e até séculos.

Deste modo, compreende-se que a mesma geração está passando por diversas mudanças e não tem preparo emocional para se modificar de maneira tão rápida, saber lidar com uma nova cultura, a transformação digital, grande quantidade de informações e trabalho remoto.

Neste contexto, o líder torna-se um agente transformacional e assume a responsabilidade de lidar com as próprias emoções e dos seus liderados e deve estar preparado, não apenas com conhecimentos técnicos, mas sim, com competências estratégicas relativas à capacidade de liderar. No novo cenário, além de tomar decisões precisa assumir lugar de destaque, visto que seu papel e atuação são fundamentais para contribuir de forma significativa no desenvolvimento emocional e profissional de sua equipe. Além de desenvolver essa inteligência emocional, é imprescindível que se valha da criatividade e inovação para sobreviver a uma nova perspectiva de futuro, sendo mais assertivo, com boas práticas de solidariedade e corrigindo as diretrizes empresariais.

Este capítulo tem como objetivo apresentar a importância da inteligência emocional aplicada à liderança após a pandemia, trazendo as bases para refletir sobre o desenvolvimento das lideranças na pós-pandemia.

\section{INTELIGÊNCIA EMOCIONAL}

Compreendendo que as mudanças são constantes e rápidas e sem saber ao certo o que se espera exatamente do futuro, uma grande parte das pessoas não 
conseguem adaptar-se a esta nova conjuntura, por não ter habilidades suficientes para lidar a realidade imediatista. Dessa forma, muitas delas podem passar por transtornos psicológicos e até físicos, sendo necessário compreender o quanto a inteligência emocional pode contribuir neste processo evolutivo.

No sentido mais amplo, a inteligência é a capacidade de avaliar uma situação, compreender e tomar a melhor decisão. A palavra inteligência, no dicionário, significa a faculdade de compreender (MICHAELIS, s/d).

Compreendendo que a inteligência é uma habilidade, significa que pode ser desenvolvida ou aperfeiçoada e que existem muitas inteligências. "A aptidão emocional é uma metacapacidade que determina até onde podemos usar, bem quaisquer outras aptidões que tenhamos, incluindo o intelecto bruto" (GOLEMAN, 2012, p.60). Com isso, percebe-se claramente que compreender a si mesmo é uma das inteligências humanas e possibilita saber reconhecer seus pontos fortes e pontos a serem desenvolvidos.

Na visão de Cury

A emoção é um campo de energia em contínuo estado de transformação. Produzimos centenas de emoções diárias. Elas se organizam, se desorganizam e se reorganizam num processo contínuo e inevitável. É essa alternância das emoções que leva os seres humanos a constantes mudanças de humores e a uma necessidade de desenvolver capacidades de autocontrole emocional (CURY, 2014, p. 34).

Conforme relatos do autor existem muitos tipos de emoções as quais se alternam diariamente e por este motivo são comuns diversos tipos de comportamentos como raiva, medo, alegria e tristeza. Por consequência, outras emoções podem surgir ao longo da vida, mediante situações vivenciadas, como: vergonha, paixão, desprezo, surpresa e amor, entre outros. Com a inteligência emocional o indivíduo aprende a lidar melhor com estas emoções, balanceando o seu lado racional com o emocional, para manter um equilíbrio entre ambos.

Esse tema - inteligência emocional - ainda não é devidamente trabalhado ao tratar-se de lideranças, visto que ocupam cargos que podem transformar a vida de muitas pessoas quando bem preparados. Sabe-se que as emoções estão presentes em todos os seres humanos e pessoas que assumem grandes responsabilidades, como gerenciar pessoas com perfis diferentes, têm a necessidade de saber se adaptar, conviver, motivar e direcionar em busca de um propósito comum.

Muitos líderes buscam inovar, empreender e aprender, lidar com novas ferramentas tecnológicas, para se readaptar ao novo contexto, e ainda atuar diante 
de diversos tipos de gerações, que convivem no mesmo ambiente. Como competências a serem desenvolvidas para essa atuação podemos citar a afetividade, solidariedade, respeito à diversidade, iniciativa e controle das emoções.

Para agir com inteligência emocional, que auxilia no desenvolvimento individual e coletivo das pessoas, são necessárias algumas habilidades, conforme o Quadro 1.

Quadro 1 - Habilidades para a inteligência emocional

\section{Inteligência emocional habilidades}

Autoconhecimento

Empatia

Resiliência

\section{Controle das emoções}

Compreender o outro

Comunicação

Fonte: os autores.

Vamos conhecê-las!

\section{Autoconhecimento}

Conhecer-se a si mesmo, ou seja, como são suas emoções e como reage a elas. Conscientizar-se disso é primordial para conseguir dar os próximos passos, evita atribulações, traz clareza para tomada de decisões, melhora a comunicação, proporciona escolhas mais assertivas e consequentemente motivação.

\section{Controle das emoções}

Conhecendo os seus sentimentos, o próximo passo será o controle, aprender a usá-los da forma correta, não se exaltar ou se calar nos momentos inoportunos. Entender como deve se comportar perante às diversas situações e saber lidar com os próprios sentimentos é o diferencial para manter a boa comunicação e facilitando a compreensão entre os pares.

\section{Empatia}

Se colocar no lugar do outro é igualmente importante para o alcance dos objetivos. A empatia, outra habilidade exigida para a inteligência emocional, é ver as situações da perspectiva do outro, como ele age, como se sente e como lida com as adversidades. Cada ser humano tem suas particularidades, vivências e 
personalidades diferentes, o que corrobora em formas diferentes de lidar com as situações. Perceber e sentir a dor do outro aumenta a chance de ter uma conexão adequada e construir uma relação de confiança e parceria.

A boa relação levará a manter um ambiente harmonioso e positivo, no qual o trabalho fluirá e os envolvidos poderão alcançar as metas com maior facilidade e leveza.

\section{Compreender o outro}

Para compreender o outro é preciso saber ouvir; dar atenção plena aos seus sentimentos, para que este se sinta acolhido; enxergar as situações da perspectiva dele para compreendê-lo melhor, pois o ser humano é único e está exposto a muitas emoções e reage de várias maneiras. Estas emoções são vivenciadas em diversos ambientes, inclusive no organizacional, e influenciarão nos relacionamentos interpessoais e desempenho das funções dos funcionários.

Tais emoções quando não compreendidas, respeitadas, tratadas e assistidas podem provocar outros problemas, os quais podem vir a interferir diretamente no desenvolvimento do indivíduo e impactar na sua qualidade de vida e na sua produtividade.

\section{Resiliência}

Segundo pesquisa realizada pelos neurocientistas argentinos Facundo Manes e Fernando Torrente (FAROL, 2020), "os efeitos da pandemia deixarão custos humanos ainda desconhecidos, porém, o cérebro tem diversas ferramentas para lidar com este tipo de situação, uma delas é a resiliência", ou seja, para desenvolver uma boa liderança, o líder deve estar presente de corpo e alma no momento da conversa, estabelecer uma escuta atenta, demonstrar confiança, respeito, criar conscientemente a empatia.

\section{Comunicação}

A comunicação faz parte do dia a dia de qualquer pessoa, seja em casa, com a família, no trabalho, na rua para pedir uma informação ou até mesmo internamente com os próprios pensamentos. A comunicação é uma das habilidades exigidas de um líder, saber comunicar-se adequadamente sempre foi um grande diferencial, principalmente em épocas de comunicação virtual. Desenvolver tais competências de comunicação torna os processos mais rápidos, gera menos mal-entendidos, o que por sua vez, mobiliza mais pessoas e traz mais felicidade. 
Uma pessoa que está com a mente aflita e com pensamentos desgovernados fala de forma veloz, agitada e gestual, sem refletir como a mensagem poderá ser recebida, ao contrário da mente serena, que demostra tranquilidade, movimentos corporais suaves, fala nem muito lenta, nem muito rápida, com expressões de gentileza e atenção ao que será interpretado.

No meio corporativo, o comportamento da liderança interfere no clima organizacional, impactando no bem-estar dos liderados e no resultado que entrega. O líder eficaz precisa transmitir confiança mesmo em momentos de crise e se comunicar de forma que todos entendam sua mensagem, sem interferências, lembrando que ela se dá de forma verbal e não verbal.

Aponta-se a necessidade de desenvolvimento de competências para liderança, durante e após a pandemia, com sabedoria e melhores estratégias melhorando o ambiente de trabalho, tanto presencial quanto em home office.

O líder que conseguir alcançar e agir adequadamente com essas habilidades, contribuirá para reduzir o nível de estresse e de ansiedade, aumentar a autoestima, equilibrar razão e emoção, além de melhorar e aumentar o poder da tomada de decisão e produtividade, com clareza de pensamentos, o que pode proporcionar crescimento pessoal e profissional.

\subsection{A DIFICULDADE DE ADMINISTRAR A INTELIGÊNCIA EMOCIONAL}

Percebe-se que inteligência racional e inteligência emocional são aspectos diferentes, pessoas muitas vezes com alto nível intelectual não consegue lidar com suas próprias emoções, muito menos ao tratar com outras pessoas. Por estes motivos existem muitos profissionais que precisam aprender que a inteligência emocional é um diferencial, principalmente quando tratamos de líderes.

A inteligência emocional aplicada aos líderes torna-se ainda mais importante, pois a estes são atribuídas diversas obrigações como motivar, ser otimista, participativo, ter espírito de equipe, ser compreensivo, saber delegar, dar e receber feedbacks eficazes, entre outras funções inerentes à função.

Que estas dificuldades estão presentes nas organizações e nas lideranças já sabemos, o que devemos fazer é buscar meios para desenvolver estas habilidades, principalmente neste cenário de incertezas proporcionado pela Covid-19. Deste modo, ressalta-se alguns pontos que se considera necessário para desenvolver a inteligência emocional.

O primeiro passo para desenvolver a inteligência emocional é conhecendo-se a si mesmo, seus próprios comportamentos e atitudes, pois quando se co- 
nhece, terá melhor controle e saberá como agir em determinadas situações. Ao conhecer seus limites ficará bem mais fácil controlar suas emoções, lidar com a pressão e estresse, o que por sua vez trará mais tranquilidade para agir, pensar e tomar decisões.

As emoções, portanto, são importantes para racionalidade. Na dança entre sentimento e pensamento, a faculdade emocional guia nossas decisões a cada momento, trabalhando de mãos dadas com a mente racional e capacitando ou incapacitando o próprio pensamento (GOLEMAN, 2007, p. 53).

Percebe-se então, o quanto é importante o líder saber usar a inteligência emocional, pois o tornará mais otimista, enxergando o lado positivo, aumentando a motivação e a empatia, levando a maior clareza na tomada de decisões, melhorando o gerenciamento do tempo, elevando a autoestima e autoconfiança.

\section{LIDERANCA}

Tem-se discutido muito sobre as competências técnicas e comportamentais dos líderes pós-pandemia. Espera-se que compreendam, se comuniquem, aumentem a produtividade de sua equipe, resolvam problemas inusitados e ainda, se mantenham íntegros. Mas, ele também está passando por todo o processo de mudanças.

Então, como ele poderá desenvolver todas estas competências e a de seus liderados?

A inteligência emocional, vem exatamente para auxiliar as duas partes. E de maneiras diferentes trabalhar a empatia, a percepção dos sentimentos, como lidar com as emoções e gerenciá-los sem perder o foco.

Para entender o papel do líder, é necessário saber quais são suas hard skills (competências técnicas) e soft skills (competências emocionais).

As hard skills são desenvolvidas conforme suas experiências na função e na formação, treinamentos e especializações, a visão técnica para a tomada de decisão. Já as soft skills depende da sua compreensão do ser humano, das suas emoções, como lidar com o outro. Como já dito anteriormente, comunicar-se com transparência e objetividade, ter empatia - capacidade de nos posicionar perante os sentimentos dos outros, ser simpático - e compartilhar afinidades.

A liderança deve ser mais audaciosa, criativa, ser confiante, empreendedora, capaz de incentivar e influenciar seus liderados em prol dos objetivos e metas, além de conciliar os interesses individuais e do grupo. 
Não era esperado, que seria uma turbulência tão grande como essa, a Covid19, e que atingiria todos os níveis, fazendo com que, após a pandemia, os líderes administrem as empresas e pessoas com atenção maior, se valendo da inteligência emocional para lidar com os novos sentimentos e mudanças na execução dos seus trabalhos.

Apesar da liderança vir se transformando, ao longo do tempo, em 2021 é mais que necessário rever novamente suas atitudes para lidar com este novo mundo, no qual é preciso diferenciar o líder do gerente.

Gerente é diferente de ser líder, pois esta é a função dada a alguém, e neste caso, poderá simplesmente ser a autoridade que se preocupa somente com as metas que deverão ser alcançadas e como o plano de ação será executado. É quem determina os procedimentos, modelos a seguir, há somente a administração dos recursos humanos, sem se preocupar com o bem-estar de todos, numa relação na qual os conflitos não são bem-vindos, e o que se leva em consideração são as metas alcançadas.

Liderança é uma questão de atitude que acontece ao se relacionar com as pessoas, na qual o comportamento do líder leva as pessoas a seguirem-no, influenciados pelas suas ações e naturalmente desenvolvem suas ideias e as executam.

São pessoas flexíveis, se adaptam às situações e tiram boas lições dos erros e acertos, apoiam seus colaboradores, mas não quer dizer que não corrija ou seja enérgico em suas atitudes. Tem responsabilidades a serem cumpridas, mas o fazem de maneira que todos colaborem, entreguem resultados, mas que estejam motivados e satisfeitos, aumentando o nível de produção e entrega.

Ser líder é ter empatia, visão do negócio e ser aberto a inovações, enxerga os conflitos e embates como uma forma de ensinamento e desenvolvimento para evolução do negócio, ações que possam agregar e melhorar todo o processo. Seu comprometimento não se dá só em resultados, mas também no bem-estar daqueles que estão à sua volta.

Já era previsto que as pessoas com cargos de liderança tivessem essas competências ou pelo menos que já estivessem se desenvolvendo, mas esta não é a realidade, muitos continuam somente na posição de gerentes e agora, num futuro próximo de pós-pandemia, serão necessárias estas e muitas outras competências.

Com o distanciamento social e o home office os colaboradores estão mais inseguros, muitas vezes, emocionalmente frágeis e é necessário que a liderança 
se mantenha próxima, esteja atenta, tenha clareza e esteja aberta a ouvi-los, ou seja, precisará usar a inteligência emocional como mais uma habilidade.

Conforme publicação na revista eletrônica Simonato (2020), “[...] O Líder de $\mathrm{A}$ a $\mathrm{Z}$ é sensível às dores da equipe, aos seus medos e preocupações, desta forma, ele encontra maneiras de ajudá-la com bastante inteligência emocional, equilíbrio e dedicação [...]”. Ele também deve procurar meios para manter o equilíbrio mental, por meio de atividades físicas, meditações, e outras atividades.

O líder deverá ser a fortaleza da equipe e se adaptar antes mesmo do que os outros. Outras características abordadas no material, é que o líder deve ser solidário para auxiliar a equipe nas questões emocionais, motivá-la para que continue a apresentar resultados e fazer as pessoas acreditarem em dias melhores e que sairão mais fortes desta crise.

...Em momentos como esse, que tal reaprender a conviver, reaprender a improvisar, lidar com recursos escassos, a retroceder se preciso for. Devemos reaprender a economizar, viver com o suficiente e voltar a nos preocupar com as pessoas. Devemos ser mais humanos. Pensar em flexibilidade de horários para os nossos colaboradores, gerando melhor qualidade de vida, produtividade e engajamento (SIMONATO, 2020).

\subsection{COMPETÊNCIAS DA LIDERANÇA PÓS-PANDEMIA}

Num mundo imprevisível, sem saber o que acontecerá após a passagem desta crise, ações são tomadas mesmo sem saber como será o futuro, o compartilhamento de responsabilidades será imprescindível, a liderança deverá ouvir e decidir conjuntamente qual melhor medida para aquele momento, facilitando a união da equipe e melhorando a produtividade. Esta ação deverá ser levada após a pandemia, fortalecendo vínculos sociais, emocionais e profissionais, importante para a boa saúde mental também.

A empatia é uma das habilidades mais comentadas do momento, todos estão fragilizados e necessitam que o outro entenda suas preocupações, seus sentimentos, medo, raiva, dor e outras mais. Se o líder souber lidar com esta situação, ter a empatia para ajudar os liderados, estes sairão mais fortalecidos e confiantes para enfrentar o novo normal.

A criatividade e a inovação também serão duas habilidades muito requisitadas após a pandemia, tanto dos gestores quanto de sua equipe. A liderança deverá reconhecer e saber desenvolver cada indivíduo e se beneficiar da criatividade para implementação da inovação e alavancar os resultados. 
[...] O que os líderes precisam durante uma crise não é um plano de resposta pré-definido, mas sim comportamentos e mentalidades que os impeçam de reagir de maneira excessiva ou exagerada aos acontecimentos da véspera e os ajudem a olhar para o futuro[...] (MCKINSEY \& COMPANY, 2020).

As boas ações plantadas durante a crise serão fundamentais para que a equipe, após o término, e que não se pode dizer que será o fim e sim um novo começo, possa ser mais otimista e trabalhe com mais tranquilidade.

\subsection{CASES DE SUCESSO EM TEMPOS DE PANDEMIA}

Um exemplo de empatia é o que a Locaweb, empresa líder em hospedagem de sites, tem proporcionado aos seus funcionários em home office - 97\% do seu contingente. Preocupados com a saúde física, emocional e financeira promoveram o programa Conexão Saúde, que disponibiliza lives internas com dicas de alimentação, treinamento funcional, orientação profissional, sessões de meditação e yoga, organização de finanças e happy hour (CAMPOS, 2020). Essas ações ajudam a melhorar a vida pessoal dos funcionários e também a vida profissional, reduzindo o estresse e aumentando a qualidade de vida e a criatividade. Tudo isso contribui para manter um bom clima organizacional e proximidade com os colaboradores.

Para se reinventar, as organizações se reuniram e lançaram o projeto \#VamosVirarOJogo. Os idealizadores - César Sousa, fundador e presidente do grupo Empreenda, juntamente com o presidente e fundador da Verity Group, Alexandro Barsi e o fundador e presidente da Simpress, Vittorio Danesi, - reuniram cerca de 450 empresas para a troca de experiências e estratégias durante a pandemia e após a pandemia. (ISTOÉ DINHEIRO, 2020)

Num modelo sem cunho político, apartidário e sem custos, participam do projeto empresas como Carrefour, Magazine Luiza e 3M, entre outras, e esperam que o número de apoiadores aumente. O objetivo é levar as boas práticas executadas durante este período para outras empresas, contadas por meio de suas experiências. Desta forma, muitos também poderão implantar as novas estratégias, melhorando o desempenho e os resultados das organizações.

As empresas vêm reunindo forças para manter-se no mercado e compreenderam que juntas podem se fortalecer se valendo da criatividade organizacional, inovação e inteligência emocional.

Outra instituição que adotou medidas para amparar os colaboradores, melhorar o ambiente de trabalho em casa, foi a MindBe, especializada em expe- 
riência do consumidor e teleatendimento, disponibilizou computadores, modens para o acesso à internet e uma ajuda de custo para gastos extras. E pensando na saúde de todos, diariamente uma psicóloga organizacional entra em contato, analisa os colaboradores e, dependendo da situação, o trabalhador é encaminhado para um psicólogo clínico e seus custos pagos pela organização. Uma técnica de enfermagem, também verifica as condições dos indivíduos e os encaminha conforme necessário. Todo atendimento das profissionais da saúde é realizado através de videoconferência, minimizando os riscos ocasionados pela pandemia. Além destas práticas, viabiliza empréstimos financeiros, mas antes passam por uma educação financeira, a fim de ensiná-los a se reorganizar e conscientizá-los financeiramente.

Inicialmente as ações adotadas foram para proteger os funcionários, mas o CEO da MindBe, Vito Chiarella, constatou que houve aumento da produtividade, melhora na eficiência de atendimento e clientes mais satisfeitos.

É notado que a pandemia foi um acelerador para as transformações tecnológicas, otimização de trabalho e avanço da indústria 4.0, e fez com que as pessoas também tivessem que se adaptar rapidamente, provocando muitos conflitos emocionais e os líderes, por sua vez, que também passaram por estas experiências, necessitam estar preparados, tanto emocionalmente quanto tecnicamente para o alcance dos objetivos da empresa.

\subsection{E 0 FUTURO?}

Conforme a Crescimentum (2020), recentemente a Gartner realizou uma pesquisa, que revelou " $80 \%$ da força de trabalho, $92 \%$ dos gerentes e $77 \%$ dos líderes seniores já se sentiam mal preparados para o futuro".

Se não se sentiam bem preparados, agora foi uma corrida para ficarem prontos, mas sabe-se que com as incertezas sobre o futuro, o caminho será mais árduo e difícil. Necessitarão desenvolver cada vez mais as suas competências emocionais para lidar com o novo.

As organizações deverão focar em treinamento e desenvolvimento de toda a equipe para minimizar os estragos ocasionados pelo despreparo e estresse. É traçado um novo perfil de competências para a pós-pandemia, a liderança deverá ser flexível, mas muito mais resiliente, empática, ágil e confiável, além de desenvolver sua habilidade crítica para lidar com o momento de incertezas.

Uma boa parte das empresas deverão migrar definitivamente para o home office, o controle de trabalho será mais intenso, resultados deverão ser entregues 
no prazo, apesar da flexibilização da jornada de trabalho. Para manter a socialização das equipes, reuniões e momentos de descontração, como planejar o café da manhã virtual, alguns minutos para que todos confraternizem será ótimo, garantindo uma equipe unida, apesar da distância.

A mudança da forma de pensar, o mindset da liderança é o que faz toda a diferença na busca de soluções para os desafios, esforçando-se para realizar o impossível, aprendendo com os erros e experiências para alcançar os objetivos da empresa. São pessoas que têm uma visão além da crise, que procuram novas oportunidades dentro do caos, dominam os processos para o alcance do sucesso, tem foco no desenvolvimento individual e coletivo, motivação e responsabilidade.

\section{CONSIDERAÇÕES FINAIS}

O mundo sempre esteve em transformação, mas com a chegada da pandemia houve a aceleração desse processo. Empresas tiveram que se reinventar do dia para a noite, pessoas tiveram que se adaptar, principalmente no que tange à liderança, que é responsável pelas estratégias, resultados e desenvolvimento humano nas companhias.

Neste contexto, a liderança é a persona que deve estar mais preparada para o novo amanhã, pois lhe cabe a responsabilidade sobre suas ações, dos colaboradores e parceiros em busca do propósito da organização.

Medos, inseguranças, ansiedades e estresses causados pela chegada da Covid-19, exige do líder resiliência e flexibilidade voltada para a gestão 4.0, na qual a tecnologia tem papel de destaque.

A inteligência emocional é o grande diferencial para lidar com os desafios desta realidade e vem para agregar novas habilidades em prol da obtenção de resultados além do esperado, e para manter equipes mais unidas e conectadas para que o trabalho seja leve, apesar de intenso.

A criatividade, que já vinha sendo discutida como uma competência importante, será essencial, dando espaço aos colaboradores exporem suas ideias, realizá-las e, se no caminho houver erros, possam reavaliar e recomeçar, sem que o medo e a ansiedade possam impedir a criação de novas soluções. Ou seja, se o líder usar da inteligência emocional para amparar o seu colaborador e manter o equilíbrio da equipe, com certeza, conseguirá soluções que minimizem os danos e melhorem a performance de todos. 
Espera-se que este capítulo tenha contribuído para o conhecimento de novas habilidades comportamentais necessárias para o crescimento e transformação da nova liderança.

\section{REFERÊNCIAS}

BOTELHO, Eduardo Ferreira. Do gerente ao líder - A evolução do profissional, 2.ed. São Paulo: Ed. Atlas, 1991.

CAMPOS, Lais. 7 iniciativas de empresas para apoiar os colaboradores em meio à pandemia do coronavírus. Forbes. Disponível em: https://forbes.com.br/ colunas/2020/04/7-iniciativas-de-empresas-para-apoiar-os-colaboradores-emmeio-a-pandemia-do-coronavirus/\#foto2. Acesso em: 14 jul. 2020.

CHIAVENATO, I. Gerenciando Pessoas: o passo decisivo para a administração participativa. 3. ed. São Paulo: Makron Books, 1997.

CORTELLA, Mário Sergio; MUSSAK, Eugênio. Liderança em Foco. São Paulo: Ed. Papirus, 2013.

CURY, Augusto. Treinando a Emoção para ser Feliz. São Paulo: Academia de Inteligência, 2001.

D’AURIA, Gema, SMET, Aaron De. Liderança em (uma) crise: reagindo ao surto de coronavírus e a desafios futuros. Mckinsey \& Company. Disponível em: https://www.mckinsey.com/business-functions/organization/our-insights/ leadership-in-a-crisis-responding-to-the-coronavirus-outbreak-and-futurechallenges/pt-br. Acesso em: 09 jul. 2020.

DINIZ, Arthur. Como preparar a liderança para atuar no novo normal? Crescimentum. Disponível em: https://crescimentum.com.br/como-preparar-alideranca-para-atuar-no-novo-normal/. Acesso em: 11 jul. 2020.

Empresas se reúnem para buscar soluções para o pós-pandemia. IstoÉ Dinheiro. Disponível em: https://www.istoedinheiro.com.br/empresas-se-reunem-parabuscar-solucoes-para-o-pos-pandemia/. Acesso em: 13 jul. 2020.

GOLEMAN, Daniel Ph.D. Inteligência emocional: a teoria revolucionária que define o que é o ser inteligente, Rio de Janeiro, 2007.

Juliano, Jean Clark, Felipe, Irene Monteiro. O tear da vida - Reflexões e vivências terapêuticas, Ed. Summus, São Paulo, 2017. 
MARSHALL B. Rosenberg. Comunicação não violenta: técnicas para aprimorar relacionamentos pessoais e profissionais, Ed Agora: São Paulo, 2006. MICHAELIS - Dicionário Brasileiro da Língua Portuguesa. Disponível em: https://michaelis.uol.com.br/moderno-portugues/busca/portugues-brasileiro/ inteligencia/. Acesso em: 04 jul. 2020.

PALANGANA, Isilda Campaner. Desenvolvimento e Aprendizagem em Piaget e Vigotski - A relevância social, Ed. Summus, São Paulo, 2015.

Pesquisa mostra impactos do cérebro contra o estresse do isolamento. Farol da Bahia. Disponível em: https://www.faroldabahia.com.br/noticia/pesquisamostra-impactos-do-cerebro-contra-o-estresse-do-isolamento. Acesso em: 07 jul. 2020.

SIMONATO, Marcelo. Em tempos de pandemia, qual o papel do líder? RHpraVOCE. Disponível em: https://rhpravoce.com.br/posts/em-tempos-depandemia-qual-o-papel-do-lider. Acesso em: 09 jul. 2020. 